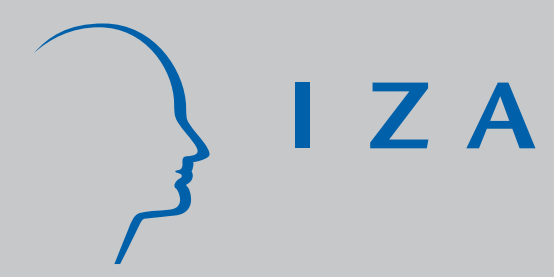

IZADP No. 1451

Is the Collective Model of Labor Supply Useful for Tax Policy Analysis? A Simulation Exercise

Olivier Bargain

Nicolas Moreau

J anuary 2005 


\title{
Is the Collective Model of Labor Supply Useful for Tax Policy Analysis? A Simulation Exercise
}

\author{
Olivier Bargain \\ IZA Bonn \\ and DELTA, Paris
}

Nicolas Moreau

Université Laval and CIRPÉE

Discussion Paper No. 1451
January 2005

IZA
P.O. Box 7240
53072 Bonn
Germany

Phone: +49-228-3894-0

Fax: +49-228-3894-180

Email: iza@iza.org

\begin{abstract}
Any opinions expressed here are those of the author(s) and not those of the institute. Research disseminated by IZA may include views on policy, but the institute itself takes no institutional policy positions.

The Institute for the Study of Labor (IZA) in Bonn is a local and virtual international research center and a place of communication between science, politics and business. IZA is an independent nonprofit company supported by Deutsche Post World Net. The center is associated with the University of Bonn and offers a stimulating research environment through its research networks, research support, and visitors and doctoral programs. IZA engages in (i) original and internationally competitive research in all fields of labor economics, (ii) development of policy concepts, and (iii) dissemination of research results and concepts to the interested public.
\end{abstract}

IZA Discussion Papers often represent preliminary work and are circulated to encourage discussion. Citation of such a paper should account for its provisional character. A revised version may be available directly from the author. 


\section{ABSTRACT \\ Is the Collective Model of Labor Supply Useful for Tax Policy Analysis? A Simulation Exercise*}

The literature on household behavior contains hardly any empirical research on the withinhousehold distributional effect of tax-benefit policies. We simulate this effect in the framework of a collective model of labor supply when shifting from a joint to an individual taxation system in France. We show that the net-of-tax relative earning potential of the wife is a significant determinant of intrahousehold negotiation but with very low elasticity. Consequently, the labor supply responses to the reform are entirely driven by the traditional substitution and income effects as in a unitary model. For some households only, the reform alters the intrahousehold distribution in a way that tends to change normative conclusions. A sensitivity analysis shows that the collective model would be required if the tax reform was both radical and of extended scope.

JEL Classification: C71, D11, D12, H31, J22

Keywords: collective model, intrahousehold allocation, household labor supply, tax reform

Corresponding author:

Olivier Bargain

IZA Bonn

P.O. Box 7240

53072 Bonn

Germany

Email: bargain@iza.org

\footnotetext{
* We are especially grateful for comments and advice from François Bourguignon and François Laisney as well as helpful suggestions from Denis Beninger, Richard Blundell, Martin Browning, Pierre-André Chiappori, John Cockburn, Olivier Donni, Bernard Fortin, Stephen Gordon, Guy Lacroix, Valérie Lechene, Costas Meghir, Philip Merrigan, Nathalie Picard and Catherine Sofer. An early version of the paper has benefited from comments of the participants in various conferences (EEA, ESEM, EALE, journées CIRPÉE and séminaire Jourdan) and in the one-year project "Welfare analysis of fiscal and social security reforms in Europe: does the representation of family decision process matter?", partly financed by the EU, General Directorate for Employment and Social Affairs, under grant VS/2000/0778. This paper was partly written when N. Moreau worked at GREQAM. All errors remain ours.
} 


\section{Introduction}

The design of an optimal income taxation of households is a central issue in economic policy. Apps and Rees $(1988,1996,1999 a, 1999 b)$ have extended earlier work from Boskin and Sheshinski (1983) in two crucial dimensions. The first one is domestic production, the second is that household decision making can be thought of as the outcome of a negotiation between spouses who may well have different preferences. $^{1}$ This extension to a multi-utility framework is based on the collective approach from Chiappori (1988, 1992) and Apps and Rees (1988) which only assume Pareto efficiency of the household decisions.

In the 1988 paper, Apps and Rees are concerned by the implication of the tax system on distribution within households. Their results, completed by Brett (1998)'s analysis of distributional issues of tax reforms, have remained purely theoretical. As noted in Apps and Rees (1999b), within-household distributional effects, even if potentially important when analyzing tax policy reforms, have been the subject of hardly any empirical research.

The contribution of the present paper is twofold. First, we question the importance of such intrahousehold redistribution resulting from a radical tax reform. We precisely tackle the case of a shift from current joint taxation to individual anonymous taxation in France. ${ }^{2}$ Second, we simulate a collective model of labor supply with taxation. The simulation methodology relies on Laisney (2002) and the model is calibrated through heterogeneous bargaining rules and unobserved preference parameters. Laisney (2002) use the general definition of Pareto-efficiency to circumvent the possible nonconvexity of utility sets. Instead, we assume that couples play ex-ante "collective mixed strategies" so that only convex hulls are considered. This allows us to rely on the maximization of a linear household welfare function in which the weights on individual utilities give a measure of the balance of power.

Calibration is carried out on French data from the 1995 wave of the European Community Household Panel (ECHP95, hereafter), using observed work hours of spouses. The empirical identification of the model requires extra-assumption, namely that some aspects of individual preferences - but not all - remain the same after marriage. There follows an estimation of the calibrated balance of power on distribution factors, including a proxy for the wife's relative net earning power in the couple. This variable is found to be a significant determinant of intrahousehold negotiation. However, the elasticity of the balance of power with respect to this variable is extremely low. Subsequently, the exercise suggests that even in the case of a radical policy reform, the distributional effect is of too limited scope to alter average results regarding labor supply responses or individual welfare. One could conclude that the unitary model is a

\footnotetext{
${ }^{1}$ This contrasts with the traditional "unitary" representation where household behavior is assumed to result from the maximization of a single utility function.

${ }^{2}$ We do not consider the case of a selective system with separate tax schedules for first and second earners.
} 
sufficient approximation when looking at the impact of taxes on household behavior. Instead, we suggest that further effort should be made to assess the distributional effect of various tax reforms when using cooperative models with more structure than the collective setting.

The outline of the paper is as follows. Section 2 presents the approach used to simulate collective rationality. In section 3, we describe the reform. Section 4 deals with the analysis of its potential impacts on individual labor supply and individual welfare, with and without account of distributional effects. Section 5 concludes the text.

\section{Simulation of a collective model of labor supply with taxation}

Collective models introduced by Chiappori $(1988,1992)$ are a substantial improvement in the modelling of individuals living in couples. First, several studies have shown that the restrictions coming from the collective model are seldom rejected by the data on couples, whereas those associated with the unitary model often are. ${ }^{3}$ Second, collective spouses play a cooperative game but the bargaining solution is unspecified so that the model encompasses both the unitary representation and other intrahousehold negotiation models such as Horney and McElroy (1981) and Manser and Brown (1990). Third, wages, prices, non labor income and other 'distribution factors' are allowed to influence the balance of power between spouses and the subsequent intrahousehold distribution of wealth and welfare. ${ }^{4}$ The richer behavioral implications of the collective model may have serious consequences for policy analysis.

A "natural" way to assess the effects of a tax reform in a collective setting would be first to estimate a model from observed labor supplies. However, in the collective framework, no simple model and no simple econometric method are available yet accounting for the distinction between participation and hours of work (see Blundell and al., 2001) as well as for a tax-benefit system leading to non-linear budget sets (see Donni and Moreau, 2002). Consequently, we opt for a simulation approach so that our model can incorporate (i) preferences which are not restricted to the egoistic or 'caring' (à la Becker) cases as in most empirical applications of collective models, (ii) non-linear budget sets, (iii) discrete labor supplies, which account for participation and seems a lot more realistic than continuous worked hours in the case of the French labor market. We introduce in a fully parameterized collective model some heterogeneity between households through one preference parameter (common to husband and wife) and the intra-household bargaining rule. The empirical identification of the model is completed through extra assumptions on

\footnotetext{
${ }^{3}$ See for instance Browning and Chiappori (1998) or Chiappori, Fortin and Lacroix (2002).

${ }^{4}$ Distribution factors are socio-economic variables that are likely to influence the conditions in which negotiation between spouses takes place but do not influence directly either the individual preferences or the budget constraint. See Bourguignon and al. (1995) for a complete discussion on distribution factors. See also McElroy (1990) for the related notion of "extrahousehold environmental parameters".
} 
preferences.

\subsection{A collective model with discrete choices and taxation}

\subsubsection{Collective rationality}

We choose a definition of the collective rationality given in Chiappori (1992), namely the maximization by the household of a family welfare function:

$$
\begin{array}{lr}
\underset{c_{f}, c_{m}, h_{f}, h_{m}}{\operatorname{Max}_{2 . t .}} & \mu(\theta) U_{f}\left(c_{f}, h_{f}, h_{m}\right)+(1-\mu(\theta)) U_{m}\left(c_{m}, h_{m}, h_{f}\right) \\
\text { s.t. } & c=c_{f}+c_{m} \leq g\left(w_{f} h_{f}, w_{m} h_{m}, y_{0}, \zeta\right)
\end{array}
$$

where $c_{i}$ represents the private individual consumption and $h_{i}$ the labor supply of spouse $i=f, m$. Total consumption, equivalent to total disposable income in such a static framework, depends not only on individual earnings but also on nonlabor income $y_{0}$, on household socio-demographic characteristics $\zeta$ (that can influence the computation of the taxes paid or the benefits received) and on the tax-benefit system $g() .{ }^{5}$ We assume that the budget constraint is binding. The weights on individual utilities are a reduced form of the intrahousehold negotiation and depend on the set $\theta$ of all factors that can influence this negotiation (distribution factors, prices and non-labor income). Hereafter, we will refer to $\mu$ as the (wife's bargaining) power index.

\subsubsection{Discretization and nonconvexities}

We opt for a discrete choice model where the set of possible work hours reflects the actual distribution of hours for France. Non-participating men are withdrawn from the sample since they represent only a very small percentage of both single and married men (see Appendices). For the same reason, the choice of part-time work is withdrawn from the set of alternatives for men in couples. The discretization thus consists of $h_{f}=0,20,30,40,50$ hours per week for single women and women in couples and of $h_{m}=20,40,45,50,60$ (resp. 40,45,50,60) hours per week for single men (resp. men in couples) ${ }^{6}$

The discrete choice approach leads to nonconvex budget sets which consist of a collection of points. ${ }^{7}$

\footnotetext{
${ }^{5}$ Our firmulation does not distinguish between husband's and wife's nonlabor income as the the distinction is not available in the data.

${ }^{6}$ Wage prediction is needed only for the non-participating wives and is performed using the panel dimension of the survey to control for unobserved heterogeneity due to omitted individual-specific variables. We specify an error-components model with an individual random effect. Potential selection bias is not modelled explicitly but is accounted for along the lines of Verbeek and Nijman $(1992,1996)$. Results are available upon request.

${ }^{7}$ In France, other nonconvexities can arise in the budget sets of low-wage workers as the result of the means-tested minimum income scheme and the means-tested child and housing benefits. The means-test concerns total household income so that these nonconvexities are of limited importance in our sample, once restricted to two- or one-earner couples.
} 


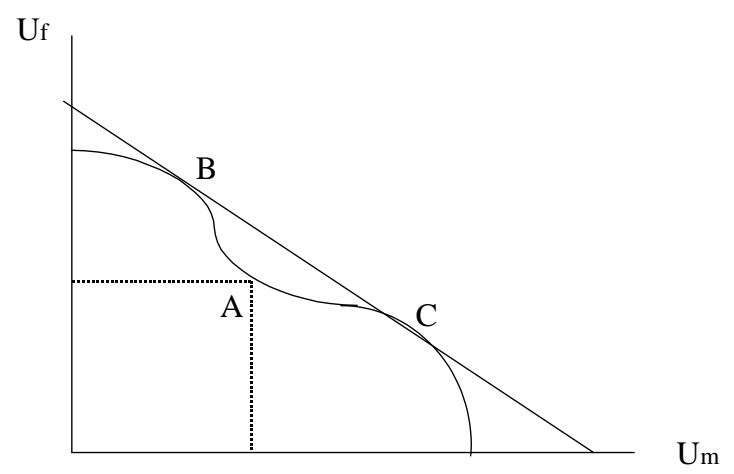

Figure 1: possibility set with VNM utilities

This may in turn cause subsequent nonconvex utility sets. To circumvent the problem, Laisney (2002) opt for a more general collective program, namely the maximization of her utility subject to a pre-allocated (or negotiated) level of his utility. The price to pay, however, is a very ad hoc definition of the power index.

Despite these possible nonconvexities in the utility sets, we consider only the convex hulls: we assume that (cardinal) individual utilities are of the Von Neumann-Morgenstern type and that all couples enlarge their domain of alternatives to include all lotteries over deterministic allocations. On Figure 1, an equilibrium $A$ located on the nonconcave part of the Pareto frontier is locally efficient, as noted by Friedman (1990). We assume that couples are globally efficient as they play a (collective) mixed strategy that increases their expected utilities. They negotiate ex-ante the final allocations for all the states of the economy and all the periods over the marriage period. ${ }^{8}$ At one point in time, if the power index $\mu$ leads to a slope $(B C)$ in the utility set, the cooperative couple is indifferent to any convex combination of $B$ and $C$. For all the other values of the power index (between 0 and 1), the frontiers of both the primitive and the convexified sets coincide and one value leads to one allocation.

\footnotetext{
${ }^{8}$ With our assumption, the power index does not need to be fixed over the periods ("full commitment" for Mazzocco, 2002). In what follows, we do not intend to model intertemporal collective behavior as in Mazzocco (2002) but rather attempt to retrieve the outcome of the bargaining process at one point in time and one state of the economy.
} 


\subsubsection{Specification of individual preferences}

We assume that preferences of single individuals are of the Stone-Geary type, written for gender $i=f, m$ :

$$
U_{i}\left(c_{i}, l_{i}\right)=\gamma_{i}^{c} \ln \left(c_{i}-\underline{c}_{i}\right)+\gamma_{i}^{l} \ln \left(l_{i}-\underline{l}_{i}\right)
$$

where $l_{i}=T-h_{i}$ is the demand for non-market time for gender $i=f, m$, and where the total time endowment $T{ }^{9}$ We assume that preferences for individuals in couples are the same except that a specific interaction term in spouses' leisures is added, so that for each spouse $i=f, m$ :

$$
U_{i}\left(c_{i}, l_{f}, l_{m}\right)=\beta_{i}^{c} \ln \left(c_{i}-\underline{c}_{i}\right)+\beta_{i}^{l} \ln \left(l_{i}-\underline{l}_{i}\right)+\delta \ln \left(l_{f}-\underline{l}_{f}\right) \ln \left(l_{m}-\underline{l}_{m}\right)
$$

Pure leisure corresponds to $l_{i}-\underline{l}_{i}$, where the minimum level of non-market time includes time spent for physiological regeneration and standardized aspects of household production, which vary with sex and with the demographic composition of the household. The cross-leisure effect takes up potential complementarity or substituability in spouses' leisure and other types of interaction between them. ${ }^{10} \mathrm{By}$ introducing this term, we relax the strong assumption of separability of individual preferences in the pairs $\left(c_{f}, l_{f}\right)$ and $\left(c_{m}, l_{m}\right)$ that is usually made in empirical studies of collective models. ${ }^{11}$

A realistic approach requires the impact of the demographic structure of the household to be modelled in several ways (see Browning, 1992). Here, children have no decision power in the household and their preferences are internalized in those of the parents. They are considered as a source of additional private consumption (for child needs) and private non-market time demand (time dedicated to childcare) for each spouse, as suggested by Deaton and Muellbauer (1980). Therefore, the minimum consumption and 'leisure' requirements $\underline{c}_{i}$ and $\underline{l}_{i}$ of each spouse depend on the number and age of the children in the household, according to (implicit) equivalence scales for $\underline{c}_{i}$ and to published information on time allocation for $\underline{l}_{i} \cdot{ }^{12}$ A full model with domestic production would require much more information than

\footnotetext{
${ }^{9}$ In what follows, $T=7 \times 24=168$ hours a week

${ }^{10}$ Theoretical distinction between individual and shared leisure in a collective framework is modelled by Fong and Zhang (2001).

${ }^{11}$ Browning and Chiappori (1998) is an exception, but their paper is not primarily concerned with labor supply. In our setting, there is no externality with respect to consumption so that the preferences are a little less general than the altruistic specification. See also Chiappori, Fortin and Lacroix (2002).

${ }^{12}$ The individual minimum consumption $\underline{c}_{i}(z)$ is set equal to $\underline{c}(z) / 2-1$. The household minimum consumption $\underline{c}(z)$ is computed as the lowest disposable income for all possible combinations of male and female labor supplies within each demographic group. Consequently, this level depends on the number of children via the implicit equivalence scale of the tax-benefit system in the lower part of the income distribution. In couples without children, the individual minimum leisure $\underline{l}_{i}$ is set arbitrarily to 92 (resp. 95) hours a week for men (resp. women). For households with children, we need to account for some minimum time requirement for household production associated with childcare: this minimum level is computed according to the French Time Allocation Survey 1998 (INSEE). Additional weekly time is set according to the age of the
} 
what is typically available in household surveys and poses a host of theoretical problems. ${ }^{13}$ Still, allowing for expenditures on children and time for childcare to be decision variables is the subject of further research. ${ }^{14}$

\subsubsection{Identification of structural parameters}

Five preference parameters $\left(\beta_{f}^{c}, \beta_{f}^{l}, \beta_{m}^{c}, \beta_{m}^{l}\right.$ and $\left.\delta\right)$ need to be identified as well as the power index $\mu$. First, we assume comparability of utility between spouses and choose to normalize both the wife's and the husband's utilities by including an adding-up constraint:

$$
\beta_{i}^{c}+\beta_{i}^{l}+\delta=1 \quad i=f, m
$$

Second, we make the crucial identifying assumption that individuals in couples keep the same relative preferences toward consumption and leisure as when they are single. This implies that: ${ }^{15}$

$$
\frac{\beta_{i}^{c}}{\beta_{i}^{l}}=\frac{\gamma_{i}^{c}}{\gamma_{i}^{l}}=\alpha_{i} \quad i=f, m
$$

where the $\gamma$ coefficients can be estimated on two samples of single men and women separately, as we see below. At this stage, we know that $\beta_{i}^{c}=\frac{1-\delta}{1+1 / \alpha_{i}}$ and $\beta_{i}^{l}=\frac{1-\delta}{1+\alpha_{i}}$. Third, heterogeneity across households is captured through the coefficient $\delta$ and the structural term $\mu$. For each household in the sample of couples, these two degrees of freedom are calibrated on the two observed labor supplies.

Using (5) and (6), it is easily shown that concavity restrictions on individual utility functions imply that $\delta \in] \delta_{\min }, \delta_{\max }[$ with:

$$
\begin{array}{ll}
\delta_{\min }=-\frac{1}{\left(1+\alpha_{i}\right) \ln \left(l_{j}-\underline{l}_{j}\right)-1} & \text { for } i, j=f, m \\
\delta_{\max } & =1 .
\end{array}
$$

youngest child: for the wife (resp.) the husband: 14 (7) hours if at least one child up to age 5, 6 (3) hours if at least one child is between 6 and 11, 5 (2) hours if at least one child is older than 11.

${ }^{13}$ Theoretical support for domestic production can be found in Chiappori (1997) and Apps and Rees (1997) when the domestic good is consumed privately. See Lewbel and al. (2001) and Chiappori and al. (2002) for household public consumption.

${ }^{14}$ Chiuri (1999) provides the first attempt to test a collective model with domestic production of childcare.

${ }^{15} \mathrm{By}$ doing so, we follow the suggestion made by McElroy (1990) concerning the use of data on singles to partly recover information about the preferences of individuals in couples. The same assumption was used by Barmby and Smith (2001) in a simpler setting with two-earner households and linearised budget restrictions. In a paper by Lewbel, Browning and Chiappori (2001), the assumption made is that singles and individuals in couples have the same preferences over a bundle of private good equivalents. 


\subsection{Estimation of relative preferences toward own leisure and consumption on single individuals}

Estimations of preference parameters are carried out (separately for single men and women) on restricted subsamples without children. This is mainly justified by the fact that single individuals who are also single parents may have unobserved characteristics that change the resulting estimates substantially. Still, the single individuals we consider may well have some children living outside the household.

We assume that the utility derived by individual $k$ for each choice $j$ and each subsequent consumption is a random function,

$$
U\left(c_{k j}, h_{j}\right)=\gamma^{c} \ln \left(c_{k j}-\underline{c}_{k}\right)+\gamma^{l} \ln \left(T-h_{j}-\underline{l}_{k}\right)+\varepsilon_{k j}
$$

where $\varepsilon_{k j}$ is a random term with mean zero. Furthermore, let us assume that this utility level is independent of the utility levels at other options, conditional on observables. This makes it possible to estimate the $\gamma$ parameters using McFadden's conditional logit model. To incorporate some observed heterogeneity, we let the $\gamma$ coefficients vary linearly with individual characteristics like age and education. We also account for unobserved heterogeneity by introducing mass points in the parameters which allow each individual to choose between different preference regimes. This methodology, suggested by Hoynes (1996), proved more efficient, both in terms of likelihood and predictive power, than the use of continuous random errors as in Random Parameter Logit models à la Van Soest (1995) or McFadden and Train (2000).

Conditioning on observables, individuals are drawn from a mixture of $R$ regimes, regime $r$ corresponding to a given pair of mass points $\left(\theta_{c r}, \theta_{l r}\right)$ for the coefficients for consumption and leisure. Each pair is observed with probability $\pi_{r}=\operatorname{Pr}\left(\theta_{c}=\theta_{c r}, \theta_{l}=\theta_{l r}\right)$, with $\sum_{r} \pi_{r}=1$. Both the mass points and their associated probabilities are estimated as parameters of the model. The unconditional choice probability (or contribution to likelihood) for a single individual choosing alternative $j$ is written:

$$
E P_{j}=\sum_{r=1}^{R} \pi_{r} \frac{\exp U\left(c_{k j}, h_{j}\right)}{\sum_{s=1}^{5} \exp U\left(c_{k s}, h_{s}\right)} .
$$

Results of the estimation are given in the Appendices. Eventually, we use the resulting estimates on singles and the relation (6) to compute individual relative preferences $\alpha$ toward consumption and leisure for all husbands and wives of the sample of couples.

\subsection{Calibration of cross-leisure preferences and bargaining rules}

We calibrate the model using the program (1) and a computer microsimulation of the budget constraint (2). For each discrete combination of labor supplies $\left(h_{f}, h_{m}\right)$, the microsimulation software computes the 
function $g()$ and provides the corresponding disposable income for the household. The computation is faithful to the 1995 French tax-benefit system and is carried out by means of the actual wages for workers and predicted wages for non-working women. To simplify the algorithm, we use our specification (7), so the first-order conditions of the program (1) with respect to $c_{f}$ and $c_{m}$ are:

$$
\begin{aligned}
c_{f} & =\underline{c}_{f}+(c-\underline{c}) \frac{\mu \beta_{f}^{c}}{\mu \beta_{f}^{c}+(1-\mu) \beta_{m}^{c}} \\
c_{m} & =\underline{c}_{m}+(c-\underline{c}) \frac{(1-\mu) \beta_{m}^{c}}{\mu \beta_{f}^{c}+(1-\mu) \beta_{m}^{c}}
\end{aligned}
$$

with $\underline{c}=\underline{c}_{f}+\underline{c}_{m}$. If we denote $p$ by $\frac{c_{f}-\underline{c}_{f}}{c-\underline{c}}$ the wife's share of "negotiable" consumption, it is entirely determined by the value of the power index:

$$
\begin{aligned}
p & =\frac{\mu \beta_{f}^{c}}{\mu \beta_{f}^{c}+(1-\mu) \beta_{m}^{c}} \\
& =p(\mu) .
\end{aligned}
$$

The first-order conditions combined with the budget constraint yield:

$$
\begin{aligned}
c_{f} & =\underline{c}_{f}+p(\mu)\left[g\left(w_{f} h_{f}, w_{m} h_{m}, y_{0}, \zeta\right)-\underline{c}\right] \\
c_{m} & =\underline{c}_{m}+[1-p(\mu)]\left[g\left(w_{f} h_{f}, w_{m} h_{m}, y_{0}, \zeta\right)-\underline{c}\right]
\end{aligned}
$$

and the collective program conditioned on the value of the unknown parameters ( $\mu$ and $\delta$ ) simplifies to:

$$
\operatorname{Max}_{h_{f}, h_{m}} \mu U_{f}\left(h_{f}, h_{m} / \delta, \mu\right)+(1-\mu) U_{m}\left(h_{m}, h_{f} / \delta, \mu\right)
$$

We vary $\delta$ over 30 steps in the bracket $] \delta_{\min }, \delta_{\max }[$ and $\mu$ over 30 steps in $[0,1]$ to obtain 900 combinations $(\mu, \delta)$; for each pair, the optimal allocation $\left\{h_{f}(\mu, \delta), h_{m}(\mu, \delta)\right\}$ is given by the maximization of the household welfare function (12). ${ }^{16}$ Assuming that couples behave according to collective rationality, the calibration consists in inverting the system:

$$
\begin{aligned}
h_{f}(\mu, \delta) & =h_{f}^{o b s} \\
h_{m}(\mu, \delta) & =h_{h}^{o b s}
\end{aligned}
$$

where $h_{f}^{o b s}$ and $h_{h}^{o b s}$ are the observed labor supplies. ${ }^{17}$

General results from the calibration are presented in Table 1. These include the distribution over the couples of the calibrated cross-leisure parameter $\delta^{*}$ and of the other preference parameters (the asterisks

\footnotetext{
${ }^{16}$ For a given $\delta$, the program considers only the allocations on the convex hull of the frontier when varying $\mu$ in the range $[0,1]$ so that the households are globally efficients as assumed above.

${ }^{17}$ Concretely, the calibrated pair $\left(\mu^{*}, \delta^{*}\right)$ for each household are found using the criterion:

$$
\left(\mu^{*}, \delta^{*}\right) \in \arg \min _{\mu, \delta}\left[h_{f}^{o b s}-h_{f}(\mu, \delta)\right]^{2}+\left[h_{m}^{o b s}-h_{m}(\mu, \delta)\right]^{2} .
$$
}

When multiple solutions occur, we choose the average couple in the set of feasible solutions. 


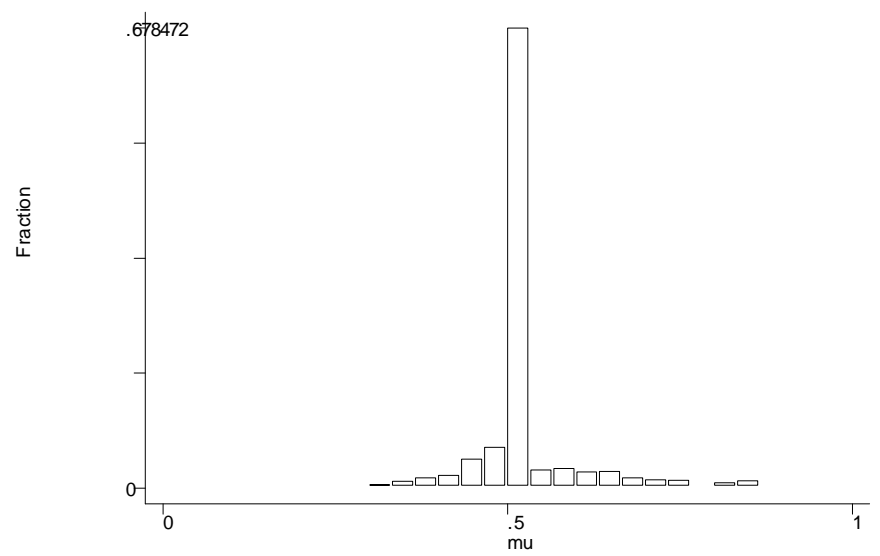

Figure 2: distribution of the power index

are omitted hereafter to simplify notation). The average and median shares of consumption for the wives is around $60 \%$ whereas the wives' bargaining power is close to $51 \%$ on average. The distribution of the power index over the sample is illustrated by Figure 2.

The cross-leisure effect $\delta$ is positive on average and increases with the number of children after the first one (cf. Table 2), accounting for possible complementarity between spouses' leisure activities. However, around $47 \%$ of the couples have a negative cross-leisure effect. The fact that leisures are substitutes in direct utility for so many households is surprising and may result from the way we import parameters estimated for singles into the preferences of individuals in couples. ${ }^{18}$ It makes sense that most of the households with a negative $\delta$ are two-earner couples. Their average weekly hours of work are 38.0 for women and 43.9 for men compared to respectively 15.6 and 41.4 in households with a positive $\delta$.

Since the grid used here is quite fine, there is not much difference between calibrated and observed hours: this is the case for $94.7 \%$ of the husbands and $99.0 \%$ of the wives. This set of calibrated hours is used as the pre-reform situation or 'collective baseline situation'.

\subsection{Estimation of the power index}

The weight $\mu$ provides a local index for the balance of power within each household, and we attempt to use exogenous factors to model it. According to Browning and Chiappori (1998), these are the prices (individual wages), non-labor income and the distribution factors, all gathered in the vector $\theta$.

\footnotetext{
${ }^{18}$ It may also comes from the fact that not all domestic production is accounted for in required levels of non-market time $\underline{l}$. Further research is needed there.
} 


\subsubsection{Distribution factors}

The income pooling assumption is one of the major criticisms of the unitary model. In our collective setting, it seems desirable to include a variable related to the relative earnings of the spouses or rather to their relative earning potential. With nonlinear taxation, net-of-tax wages are endogenous to labor supply decisions and cannot be used directly. Instead, we suggest a measure of the way the tax system modifies the relative earning power of the wife $(R E P)$. If we note $R_{h_{f}, h_{m}}$ the net earned income received by the household when she works $h_{f}$ weekly hours and he works $h_{m}$ hours, then we define her relative contribution to total net income as:

$$
R E P=\frac{R_{40,40}-R_{0,40}}{R_{0,40}}
$$

This is a simple index to account for some distortion of the tax system on the wife's relative contribution to net income, but it turns out to play a key role in what follows. If a reform alters $R E P$ dramatically, it may change the intrahousehold distribution of resources.

There are only a few examples of policy reforms which change who controls the resources within the household. The point is tackled theoretically by Lundberg and Pollak (1993, 1996), among others, with the famous "wallet to purse" reform, namely the shift from husband to wife as child allowance recipient. Empirical studies on this question can be found, for instance, in Lundberg, Pollak and Wales (1996). To our knowledge, however, nothing has been said empirically about intrahousehold distribution when considering a radical change in the taxation of couples. Considering that the present attempt is a pure simulation exercise, it would seem desirable to introduce more structure in the model. This can be done by opting for a Nash-bargaining model with internal threat points, in the fashion of Lundberg and Pollak (1993, 1996), or external threat points as in Manser and Brown (1980) or McElroy and Horney (1981). This is beyond the scope of the present study, as we are mainly interested in the implementation of the more general collective representation when accounting for taxation. ${ }^{19}$

On top of the REP variable, we simply use the relevant distribution factors that can be built from the data : the difference in age between the spouses; the difference in education level (the exogeneity of human capital accumulation is assumed); the difference in unemployment rate. Descriptive statistics are presented in Table 3.

\footnotetext{
${ }^{19}$ We do not address the question from Browning and Lechene (2001) about the collective model: the theory around this general representation of household behavior does not give any guidance as to what variables should appear in the set of distribution factors.
} 


\subsubsection{Results of the estimation}

We turn to the estimation of the power index on vector $\theta$. First, we assume the same fonctional representation for $\mu$ for both corner and interior solutions. Second, we use the logistic equation

$$
\ln \left(\frac{\mu}{1-\mu}\right)=\theta \eta+u
$$

to ensure that the predicted index lies in $[0,1]$. The regression is simply conducted by OLS method. The error term $u$ capture all unobserved and unexplained heterogeneity among households. The results of the estimation are presented in Table 4.

An important finding is that the variable $R E P$ is a significant determinant of the power index, with the expected sign. On the whole, the higher the wife's earning potential, the higher her bargaining position. However, the marginal effect of REP decreases with its level. This concave shape was suggested by a nonparametric regression of $\ln \left(\frac{\mu}{1-\mu}\right)$ on $R E P$ and appeared to be robust to all specifications tested.

As can be shown from Table 5, the elasticity of the power index to the $R E P$ variable is very low. ${ }^{20}$ At the median value of her Relative Earning Power, a $10 \%$ rise in REP translates into a $0.89 \%$ increase of the power index.

The husband's wage influences negatively his wife's bargaining power whereas her own wage has no impact. ${ }^{21}$ Also, the higher her chances to find a job on the market relative to her husband's (i.e. the higher durate), the higher her power index. The negative sign of the differential of education is unexpected. Finally, age does not significantly affect the distribution of the power index.

Interpreting the power index requires a great deal caution. First, most of the non-strictly environmental parameters probably involve identification issues. Second, one could claim that many relevant distribution factors are missing in the regression. Our interest, though, is not to predict the balance of power but to simulate the likely change in the distribution due to a variation of her $R E P$ after a change in tax policy. In the remainder of the paper, we use the predicted values of the power index with retention of residuals $\widetilde{u}$ from the estimation (household-specific unobserved heterogeneity).

\section{Description of the tax reform}

The current income tax regime in France is an extension of the splitting system to account for the presence of dependent children. Both spouses face the same marginal tax rate. We suggest a shift from

\footnotetext{
${ }^{20} \mathrm{~A}$ sensitivity analysis presented in what follows concludes that this result is not due to the use of singles' preferences as an identifying assumption (cf. Table 6).

${ }^{21}$ This result could be anticipated after running a nonparametric regression of $\ln \left(\frac{\mu}{1-\mu}\right)$ on $R E P$. No relationship between these two variables appears.
} 
this joint system to individual taxation. This is likely to increase the marginal tax rate faced by the first (higher-wage) earner and decrease the rate faced by the second (lower-wage) earner, the wife in $73 \%$ of the couples.

\subsection{Current income taxation in France}

In France, income taxation rules for year $t$ apply to income of year $t-1$ so that we use the rules of 1996 to compute taxes for the 1995 sample of couples. Taxable labor income consists of earned income net of social contributions and special contributions (deductible "CSG"). Deductions for work expenses $(10 \%)$ are also withdrawn as well as a special deduction (20\%) for salary earners. ${ }^{22}$ The progressive tax schedule, denoted by $t($ ), is a piecewise linear function with 7 marginal tax rates (from 0 to $54 \%$ ).

We describe the rules regarding married couples in what follows. Let the household total taxable income be $y=y_{f}+y_{m}$ with $y_{i}$ the taxable income of spouse $i=f, m$. To account for the family dimension, the tax schedule is applied to the equivalized taxable income $y / s$ where the number of adultequivalents $s=2+k$ is computed using the official equivalence scale for children $k$ : 0.5 for each of the two first children and 1 for each additional child. Eventually, tax liability is computed as:

$$
T=\operatorname{st}(y / s)
$$

This leads to lower marginal tax rates for married couples than for single individuals and lower still for families with children. Given the progressivity of the income tax schedule, this method of calculation implies that the deduction for children is larger in rich than in poor families and a ceiling on that deduction prevents a too large inequity.

\subsection{From joint to individual taxation}

We consider a switch from joint to individual taxation: each spouse in the household will pay an income tax based on his or her sole earned income. ${ }^{23}$ As for the treatment of the family size, we choose a natural adaptation of the existing system and assume that $k$ is equally shared between spouses. The number of adult-equivalents in the individual tax unit of spouse $i=f, m$ is then written:

$$
s_{i}=1+k / 2
$$

so that individual tax becomes:

$$
T_{i}=s_{i} t\left(y_{i} / s_{i}\right)
$$

\footnotetext{
${ }^{22}$ This is aimed at making the tax treatment of salary earnings and self-employment earnings homogeneous since the latter are generally under-reported.

${ }^{23}$ The main part of the capital income is taxed via a different system so that interferences with such type of reform are limited.
} 
and household income tax is $T=T_{f}+T_{m}$. With this reform, the rules for married couples come close to the ones for cohabiting spouses. With the individualized system, though, spouses do not have the ability to allocate $k$ freely among them.

\subsection{Direct impact on tax liabilities and welfare}

The proposed reform alters the budget constraint and leads to a new Pareto frontier. At this stage, however, we do not account for behavioral responses to the reform. The allocation $\left(h_{f}, h_{m}, p\right)$ does not change and the new location $\left(U_{f}, U_{m}\right)$ may not be on the new frontier.

Table 7 describe the variations of the tax burden after the reform: the effect on married spouses can either be negative or neutral. When their contributions to the household resources are close, both spouses are individually taxed in the same bracket as was the equivalized joint income of the couple. Therefore, they both face the same marginal tax rate as before and total tax liability of the household does not vary. This happens for $35.5 \%$ of the couples (including households paying no tax).

For all other couples, a substantial gap exists between spouses' incomes, either due to a wage gap, a difference in labor supplies or both. With the reform, the effective marginal tax rate faced by the second earner falls or remains the same whereas the one faced by the first earner rises in most cases. The latter effect tends to dominate, so that the tax burden increases. One-earner couples experience the worst losses, as the number of adult-equivalents is reduced by $1+k / 2$ after the reform. On average, the tax liability increases by 920 euros yearly and by $67 \%$ in relative terms. Many couples experience an important rise whereas their original tax burden is very low: the increase for the median couple is "only" $19 \%$.

These figures are close to the official figures proposed by the French Ministry of Finance (see Briaire and Echevin, 2002). National tax revenue from married couples increases by $21.2 \%$ with the shift from joint to individual taxation. The fact that the reform is not revenue neutral is not a matter of concern for the present exercise. First, we do not intend to compare several reforms, which would need to be done on the same cost basis. Second, neutrality would require changing the tax schedule. Researchers from the Ministry of Finance suggest that a decrease of $13 \%$ of all tax rates (in all brackets and all types of households) would achieve neutrality but would result in a huge redistribution from married couples to cohabiting couples and singles. Having in mind a bargaining model à la Manser and Brown (1980), this could dramatically change the financial situation of spouses of getting divorced (their threat point), and therefore the balance of power of married couples. Our model is not well suited to pursue this point.

Table 8 presents the impact of the reform on consumption and welfare. As the tax liability increases, total disposable income and individual consumptions decrease by $1.9 \%$ on average. Both individual 
utilities decrease as well, but slightly more for wives $(-0.27 \%)$ than for husbands $(-0.23 \%)$, as their propensity to consume is more important ( $55.4 \%$ on average, opposed to $38.5 \%$ on average for husbands). Total household welfare $W=\mu U_{f}+(1-\mu) U_{m}$ drops by $0.26 \%$.

\section{Simulation of household responses}

This section deals with the main objective of the study, namely the simulation of collective labor supply responses to tax reforms. We break down the responses in two stages. In the first step, we assume that weights on individual utilities are constant, which makes our setting a true unitary model. In a second step, we allow an additional change in the power index resulting from a change in the $R E P$ after the reform: this distributional effect is specific to the collective setting. In both cases, we analyze the labor supply responses and the subsequent changes in individual welfare.

\subsection{Unitary response to the reform}

At this stage, we treat the model as a unitary one, assuming that $\mu$ does not depend on prices or distribution factors and consequently on REP and the tax system. The decision process consists of the maximization of a fixed household welfare function as in Samuelson (1956). ${ }^{24}$ As budget constraints become less favorable on average, utility sets are likely to shrink toward the origin and unitary households optimize so that the new location $\left(U_{f}, U_{m}\right)$ be on the new frontier.

Such behavioral responses are due to the impact of the reform on the budget constraints. Individual labor supply reactions are only driven by traditional substitution and income effects. Effective marginal tax rate of first earners (resp. second earners) rise (resp. fall) on average so that substitution effects imply a likely decrease of husbands' labor supply and increase of wives' hours and participation. Indeed, $7.64 \%$ of the husbands decrease their working time whereas only $0.63 \%$ of them increase it. Among wives, $15.07 \%$ of them re-enter the labor market and $6.74 \%$ increase their working time. The income effect (a decrease in total disposable income) offsets only partially the negative substitution effect on male labor and strengthens the positive effect on female labor supply. On the whole, $21.8 \%$ of the women react to the reform when only $8.27 \%$ of the men. As noted in Table 9 , some households experience a joint reaction of both spouses (with opposite signs).

As a result, total disposable income increases by $2.9 \%$ on average. Weights on individual utilities are fixed so that the consumption share does not change and both individual consumptions increase proportionally. Details are presented in Table 10. Overall, husbands gain leisure and consumption

\footnotetext{
${ }^{24}$ Formally, Chiappori (1992) and Kooreman and Kapteyn (1992) note that such household welfare index cannot be distinguished from a unitary function since weights and preference parameters cannot be disentangled.
} 
whereas women's loss of leisure is not offset by the small consumption gain. Therefore, the reallocation of labor force within households leads to an increase in husbands' welfare but a drop in wives' utilities. Total household welfare increases by $0.05 \%$. A traditional unitary model would simply conclude that labor supply responses are slightly welfare-improving, ignoring completely the conflicting situations that may take place within households (welfare gains for husbands and welfare losses for wives). Our multi-utility framework shows that the classical substitution and income effects following a reform can be responsible for such intrahousehold redistributions of welfare, as they change the allocation of leisures. It should be noted, however, that domestic production is not formally modelled here. ${ }^{25}$

\subsection{Collective response to the reform}

We now account for the distributional effect of the reform via the $R E P$ variable. It is well known that joint taxation imposes a tax burden on the second earner through marginal tax rates that are higher than those she would normally face. As seen above, an individualization of the tax system has consequently a strong incentive effect as the net wages of second earners dramatically increase. Moreover, the net potential contribution of a second earner (resp. first earner) may increase (resp. decrease), i.e., the female Relative Earning Power (REP) may rise substantially. Note that we consider female potential earnings. Hence, even if only $64.5 \%$ of the couples experience an actual change in their tax liability, all the couples of the sample face a new value of the $R E P$ variable. With the reform, $R E P$ increases by $15 \%$ on average and in $99.7 \%$ of the couples. We briefly give the intuition of this result. Denote

$$
R E P^{*}=\frac{R_{40,40}^{*}-R_{0,40}^{*}}{R_{0,40}^{*}}
$$

the value of the $R E P$ variable after the reform and $\triangle R E P=R E P^{*}-R E P$. It comes that:

$$
\Delta R E P=\frac{R_{0,40}\left[R_{40,40}^{*}-R_{0,40}^{*}\right]-R_{0,40}^{*}\left[R_{40,40}-R_{0,40}\right]}{R_{0,40} R_{0,40}^{*}} .
$$

Denote $a$ the first expression in brackets and $b$ the second. The denominator is positive as well as $a$ and $b$. The sign of $\triangle R E P$ is given by $a R_{0,40}-b R_{0,40}^{*}$. For all households, $R_{0,40}>R_{0,40}^{*}$ as the number of adult-equivalent is automatically reduced by $1+k / 2$ in one-earner couples. If $a \geq b$, her contribution by taking a full-time job is larger after the reform and $\triangle R E P \geq 0$. This is the case for $98.6 \%$ of the couples. ${ }^{26}$ For a quarter of them, the wife is first earner $\left(w_{f}>w_{m}\right)$. We can write:

$$
a-b=\left[R_{40,40}^{*}-R_{40,40}\right]-\left[R_{0,40}^{*}-R_{0,40}\right] .
$$

\footnotetext{
${ }^{25}$ The subsequent question regarding female welfare is whether women re-entering the labor market experience an equivalent drop in their housework. Time use surveys suggest that this is unlikely. In countries where female participation is comparable to male, wives still perform much more burdensome domestic activities than husbands (for instance, see Bonke and al. (2002) for Denmark).

${ }^{26}$ Among the remaining $1.4 \%$ of the couples, only $0.3 \%$ have $a<<b$ so that $\triangle R E P<0$.
} 
Both expressions in brackets are negative or null (the reform increases the tax liability) but the absolute value of the second is larger since the lost for one-earner couples is more important. For the other threequarter (with $w_{f}<w_{m}$ ), the husband's wage is higher so that the lost $\left[R_{0,40}^{*}-R_{0,40}\right]$ is even more substantial and $\triangle R E P$ larger. Indeed, REP increases by $9 \%$ when the wife is first earner $(26 \%$ of the couples) and by $17.1 \%$ when the husband is first earner.

If vector $\theta^{\text {new }}$ incorporates the new value of the $R E P$, then the new power index is computed as:

$$
\mu^{\text {new }}=\frac{\exp \left(\theta^{n e w} \widetilde{\eta}+\widetilde{u}\right)}{1+\exp \left(\theta^{n e w} \widetilde{\eta}+\widetilde{u}\right)} .
$$

This corresponds to a change in favor of the wives in the intrahousehold negotiation. However, the elasticity of the power index to the $R E P$ variable is extremely small (see Table 5 ) so that the distributional effect that takes place is very slim. A possible explanation to this finding could be related to our empirical identification assumption, i.e the use of singles' preference parameters. We then compute several simulation exercises in the neighborhood of the estimates obtained from singles. Table 6 reports some of the results in terms of elasticities. It appears that the effect of $R E P$ on $\mu$ are even smaller in magnitude.

The female power index increases on average by $1.1 \%$. Table 11 compares the variation in both the $R E P$ variable and the power index after the reform. By construction, a shift in the balance of power in favor of the wives should increase their consumption share and their leisure and decrease male leisure. However, the distributional effect is too small to imply dramatic changes. Overall, only $0.6 \%$ of the women decrease their labor supply and only by 10 hours. As for men, $2.4 \%$ of them increase their labor supply $(0.4 \%$ by 5 hours and $2 \%$ by 10 hours). Table 12 shows that compared to the strong responses driven by the traditional effects in a unitary setting, the distributional effect has a marginal impact on labor supplies. At this stage, one may conclude that as far as work incentives are concerned, the unitary model offers a reasonable approximation of behaviors for policy analysis.

Overall labor supply increases very slightly; so does total disposable income $(+0.08 \%)$. However, the rise of the female bargaining power leads to a larger female consumption share $p$ on average (from $59.8 \%$ to $60.3 \%$ of total negotiable consumption). Consequently, women consumption increases by $0.76 \%$ whereas men consumption falls by $0.79 \%$ on average. The distributional effect is welfare-improving for the wives but decreases husbands' utility as noted in Table 13. This is true on average and for all the couples experiencing a rise in $\operatorname{REP}\left(99.7 \%\right.$ of the sample).$^{27}$ Table 14 summarizes the three steps and shows that the distributional effect tends to offset partly the welfare incidence of the unitary response. ${ }^{28}$

\footnotetext{
${ }^{27} \mathrm{As} \mu$ is larger than 0.5 on average, the variations in individual utilities result in a rise of household welfare $(+0.09 \%)$.

${ }^{28}$ Further evidence of the underlying effects on the reform, notably when looking to different family situations, is available on request.
} 
However, this counter-effect is of limited scope. With the unitary effect, $7.5 \%$ of the wives experience a welfare fall of more than $1 \%$ in magnitude (minimum: $-5.3 \%$ ) whereas $16.25 \%$ of the husbands experience a welfare rise of at least $1 \%$ (maximum: $+12.6 \%$ ). With the distributional effect, only $1.9 \%$ of the wives gain more than $1 \%$ of welfare (maximum: $+5.7 \%$ ) and $2.5 \%$ of the husbands lose more than $1 \%$ (minimum: $-11.3 \%)$.

When we distinguish between the unitary and distributional effects, it appears that welfare changes are of comparable magnitude in both cases but of limited scope in the latter. This is mainly due to the reform at stake, which targets only part of the population as poor households do not pay income tax. Therefore, we conduct a sensitivity analysis in two steps.

\subsection{Sensitivity analysis}

First, we question how sensitive the results are to the variation of the power index, both in scope and in magnitude. Second, we wonder how radical (in scope and magnitude) a reform should be to require the use of a model that accounts for distributional effects (a collective model).

Considering the fact that the income tax reform increased the power index on average by $1.1 \%$ and at most by $3.1 \%$, we conduct our sensitivity analysis by increasing the power index of all couples by $1 \%$, $2.5 \%$ and $5 \%$. The $5 \%$ increase is interpreted as an upper bound (in magnitude) of what a tax policy reform could realistically accomplish.

The impact of each respective rise of the power index on average individual labor supplies is presented in Tables 15 and 16. For a redistribution of power of limited magnitude but large scope $(\mu+1 \%$ for all couples), the effect is small. If we consider a larger magnitude, that is $\mu+2.5 \%$ (close to the maximum effect of a radical reform as the one simulated previously), then $3.6 \%$ of the wives diminish their working time $(0.5 \%$ stop working) whereas more than $10 \%$ of husbands increase it. These adjustments are not marginal and a distributional effect of that kind cannot be ignored. It may be too large, however, to be accomplished by a tax reform.

The impact on individual utilities is presented in Table 17. On Figure 3, the vertical axis displays the change (in \%) in male utility and the horizontal axis the change in female utility. It appears that there is no dramatic change in individual welfare on average. If we apply a large effect $(+2.5 \%)$ on every couples, $95 \%$ of them experience a rise in female utility of less than $1 \%$ and $92 \%$ a fall of male welfare smaller than $1 \%$.

We now focus on the $2.5 \%$ and $5 \%$ increases. ${ }^{29}$ We study the distribution of increases in $R E P$ (in percentage) over the sample so that all the couples uniformly face a $2.5 \%$ or a $5 \%$ rise of their female

\footnotetext{
${ }^{29}$ The $1 \%$ increase is what we obtained on average with the income tax reform.
} 

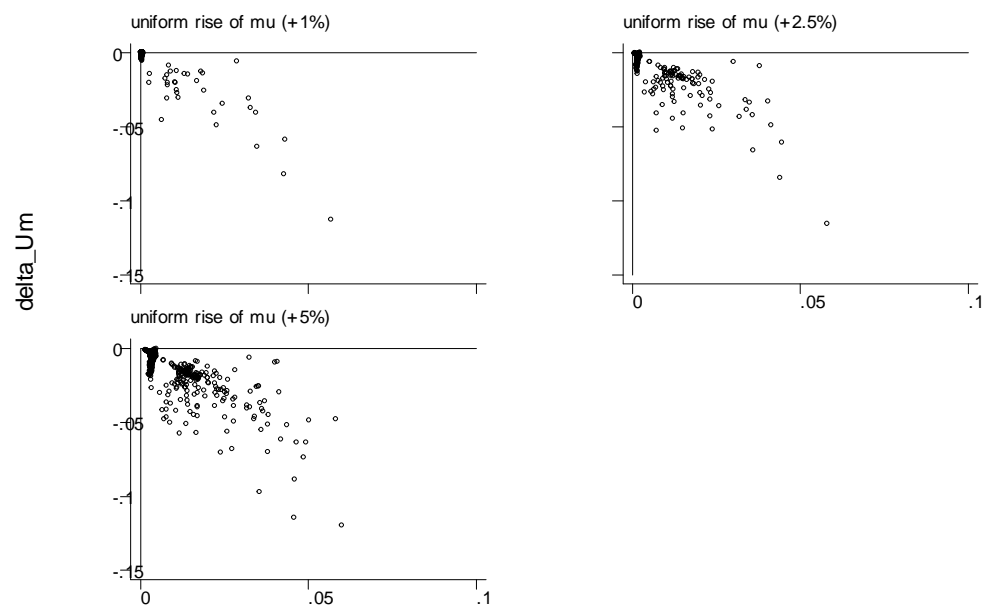

delta_Uf

Figure 3: Changes in individual utilities (in \%) resulting from a uniform rise of the power index

power index. This is compared with the distribution in the case of the income tax reform simulated previously. Results are illustrated by Figure 4 . To obtain a uniform rise of $5 \%$ of the female power index, REP must increase by $76 \%$ on average (and between $+63 \%$ and $+104 \%$ for $80 \%$ of the couples). Even in the case of a $2.5 \%$ rise, a large increase in $R E P$ is required: $+35 \%$ on average and between $+27 \%$ and $+48 \%$ for $80 \%$ of the couples. ${ }^{30}$ It is unlikely that a credible tax reform can produce such dramatic variations in her Relative Earning Power. In the case of the simulated reform, REP rises only by $15 \%$ on average (and between $+6 \%$ and $+26 \%$ for $80 \%$ of the couples).

Our results do not contradict - but complement - the income pooling test literature as in Lundberg, Pollak and Wales (1996). These authors use as a "natural experiment" the policy change in the UK that transferred a substantial child allowance from husbands to wives in the late 1970s. They find that it results in a strong distribution effect which increases expenditures on women's clothing and children's goods. However, their paper deals with consumption patterns whereas our model is calibrated on labor supplies. In our case, all the heterogeneity in the power index is assumed to be captured through the variance in individual labor supplies.

\footnotetext{
${ }^{30}$ Note that the concave relationship between $\mu$ and $R E P$ prevents respectively $5.5 \%$ and $14.6 \%$ of the couples to fullfill the required rises of $2.5 \%$ and $5 \%$.
} 

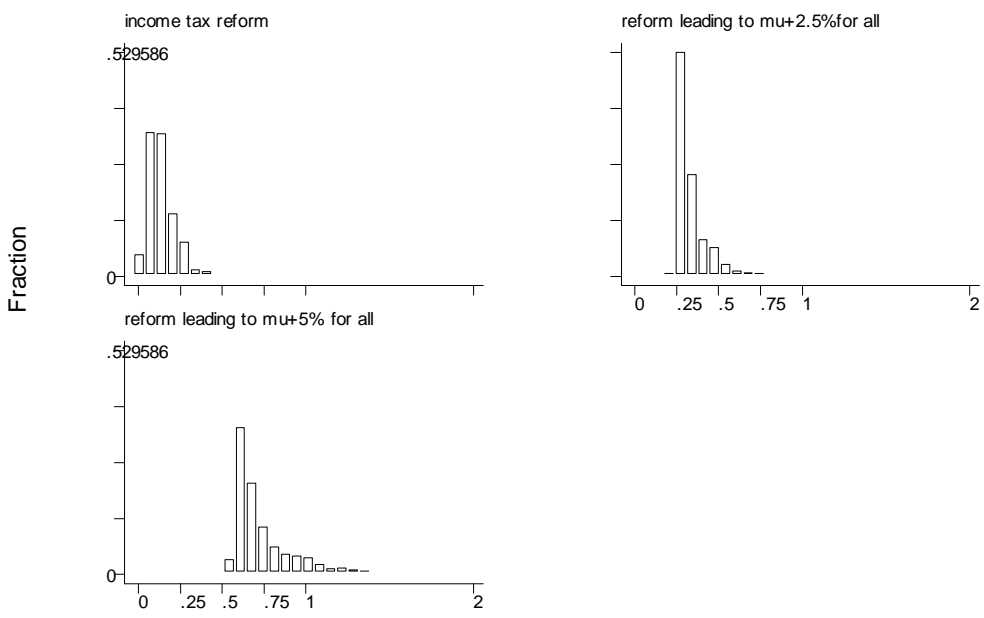

Figure 4: Distribution of the increase in REP (in \%) over the population

\section{Conclusion}

Using real data on French married couples, we have calibrated a two-utility model of labor supply where couples make Pareto-efficient decisions. Weights on individual utilities proves significantly dependent on a proxy for the wives' net relative earning power but with a very low elasticity. We simulate the shift from joint to individual taxation in France and introduce behavioral responses. First, the calibrated weights are assumed to be fixed so that the model is of the unitary type. Traditional substitution and income effects create strong incentives for second earners (mostly wives) to reenter the labor market. Second, the wives' relative earning power increases dramatically with the reform and we allow the power index to vary with it. The resulting distributional effect, which makes the model specifically collective, is too small to change policy analysis on labor supply responses. On the normative side, the multi-utility framework reveals conflicting situations between spouses: husbands seem to gain at the expense of wives after the reallocation of labor supply due to the substitution and income effects. Interestingly, the distributional effect tends to offset this result.

The scope of the welfare changes is too limited to draw clear results on average so that we conduct a sensitivity analysis. It appears that a significative change in labor supplies and individual welfare requires a dramatic change in the wife's Relative Earning Power, both in scope and magnitude, which is unlikely to be accomplished by a tax reform.

It may seem from this simulation exercise that the collective model is superfluous for tax policy analysis, as the distributional effect we capture are marginal compared to traditional effects. Does it 
mean that this distributional effect can be ignored and the unitary model used as a good approximation for analyzing tax reforms? We rather suggest that the implementation of a more structural model is desirable and that some improvements are necessary.

First, the proper choice of threat points would improve the characterization of distributional effects implied by certain tax policies. In our model, the wife's Relative Earning Power tells us which spouse contributes the most to household net income and as such, can be thought of as a determinant of underlying internal threat points.

Second, it may be the case that the nature of the reform is important. A targeted reform with a "gender tag" - as in Lundberg, Pollak and Wales (1996) - may have a stronger influence on household behavior than a reform of income taxation. It should be recognized in future empirical studies that the various components of a tax-benefit system may have a different incidence on within-household actual transfers. Money management practices can be such that the sharing rule concerning earned income is more egalitarian than the sharing of specific allowances, especially allowances which are targeted to one household member. These arguments are purely hypothetical but deserve to be investigated jointly and separately. ${ }^{31}$ They open a large research avenue, both theoretically and empirically, on the close relationship between complex sharing arrangements, the specific roles and incidence of the various taxbenefit components and outcomes such as expenditure patterns or labor supplies.

Third, our results depend partly on specific assumptions concerning discretization, functional forms and comparability of utilities. A welfare analysis along the lines of Small and Rosen (1981) or Bhattarai and Whalley (1997) could be useful. Further improvements are also needed. The minimum required consumption goes some way in the direction of subsuming public goods (like housing) but at the cost of neglecting decisions made within the household concerning the level of public consumption and its adjustment to the new bargaining environment. Maybe even more crucial when it comes to labor supply decisions in a couple, domestic production needs to be introduced, notably production of childcare.

\section{References}

[1] Apps, P.F. and R. Rees (1988): "Taxation and the Household Production", Journal of Public Economics, 35, 355-369.

\footnotetext{
${ }^{31}$ Maitra and Ray (2001) go in that direction by testing income pooling of the various income components in addition to income pooling among spouses. As various tax-benefit instruments may have different impact on household outcome, the different components of unearned income (asset returns, pensions, transfers) may have different behavioral and welfare impact. Interestingly, they find that men and women are much less likely to pool their transfer receipts than other type of income.
} 
[2] Apps, P.F. and R. Rees (1996), Labour Supply, Household Production and Intra-family Welfare Distribution, Journal of Public Economics, 60, 199-219.

[3] Apps, P.F. and R. Rees (1997): "Collective Labor Supply and Household Production" (Comments), Journal of Political Economy, 105, n1, 178-190.

[4] Apps, P.F. and R. Rees (1999a): "Joint vs. individual taxation in models of household production". Journal of Political Economy, 107, 393-403.

[5] Apps, P.F. and R. Rees (1999b): "On the taxation of trade within and betweenhouseholds". Journal of Public Economics, 73, 241-263.

[6] Barmby, T. and N. Smith (2001): "Household Labor Supply in Britain and Denmark: Some Interpretation Using a Model of Pareto Optimal Behavior", Applied Economics, 33, 1109-1116.

[7] K. Bhattarai and J. Whalley. (1997): "Discreteness and the Welfare Cost of Labor Supply Tax Distortions", NBER working paper, 6280.

[8] Blundell, R.W. , P.-A. Chiappori, T. Magnac and C. Meghir (2001): "Collective Labor Supply: Heterogeneity and Nonparticipation", mimeo, University College London.

[9] Bonke, J., N.D. Gupta and N. Smith (2002): "Do Housework and Leisure Harm Your Career ?", Presentation for the conference of the European Association of Labor Economics, Paris Sorbonne.

[10] Bourguignon, F., M. Browning and P.-A. Chappori (1995): "The Collective Approach to Household Behavior", DELTA working paper, 95-04.

[11] Brett, C. (1998) : "Tax Reform and Collective Family Decision-Making", Journal of Public Economics, 70, 425-440.

[12] Briaire, D. and D. Echevin (2002): "Analyse des réformes fiscales à partir d'un outil de microsimulation: application à l'individualisation de l'impôt", Direction de la Prévision, French Ministry of Finance.

[13] Browning M. (1992): "Children and Household Economic behavior", Journal of Economic Literature, vol. $30, \mathrm{n}^{\circ} 3,1434-1475$.

[14] Browning M. and V. Lechene (2001): "Caring and Sharing: Tests Between Alternative Models of Intra-household Allocation", Working Paper, Oxford University.

[15] Browning, M. and P.-A. Chiappori (1998): "Efficient Intra-Household Allocations: A General Characterization and Empirical Tests", Econometrica, 66, 1241-1278. 
[16] Chiappori, P.-A. (1988): "Rational Household Labor Supply ", Econometrica, 56, 63-89.

[17] Chiappori, P.-A. (1992): "Collective Labor Supply and Welfare", Journal of Political Economy, 100, 437-467.

[18] Chiappori, P.-A. (1997): "Introducing Household Production in Collective Models of Labor Supply", Journal of political Economy, 105, 191-209.

[19] Chiappori, P.-A., B. Fortin and G. Lacroix (2002): "Marriage Market, Divorce Legislation and Household Labor Supply", 110, Journal of Political Economy, ,37-72.

[20] Chiappori, P.-A. , R.W. Blundell and C. Meghir (2002): "Collective Labor Supply with Children", IFS working paper, W02/08.

[21] Chiuri, M.-C. (1999): "Intra-Household Allocation of Time and Resources: Empirical Evidence on a Sample of Italian Households with Young Children”, TMR Progress Report n 5 , Tilburg.

[22] Deaton, D.A. and J. Muellbauer (1980): "Economics and Consumer Behavior", Cambridge University Press.

[23] Donni, O. (2000): "Essais sur les modèles collectifs de comportement du ménage", PhD thesis, EHESS.

[24] Donni, O. (2002): "Collective Household Labor Supply: Non-Participation and Income Taxation", Journal of Public Economics, forthcoming.

[25] Donni, O. and N. Moreau (2002): "Une estimation d'un modèle collectif d'offre de travail avec taxation", Annales d'Economie et de Statistiques, 62, 55-83.

[26] Fong, Y. and J. Zhang (2001): "The Identification of Unobservable Independent and Spousal Leisure", Journal of Political Economy, 109, 191-202.

[27] Fortin, B. and G. Lacroix (1997): "A Test of the Neo-Classical and Collective Models of Household labor Supply", Economic Journal, 107, 933-955.

[28] Friedman, J.W. (1990): "Game Theory with Applications to Economics", Oxford University Press.

[29] Hoynes, H. (1996): "Welfare Transfers in Two-Parent Families: Labor Supply and Welfare Participation Under AFDC-UP", Econometrica, 64, 295-332.

[30] Kooreman, P. and A. Kapteyn (1992): "Household Labor Supply: What Kind of Data Tell Us How Many Decision Makers There Are?", European Economic Review, 36, 365-371. 
[31] Laisney F. (2002) (editor): "Welfare Analysis of Fiscal and Social Security Reforms in Europe: Does the Representation of the Family Decision Process Matter?" Final Report on EU-project VS/2000/0778, Mannheim, ZEW.

[32] Lewbel, A., P.-A. Chiappori and M. Browning (2001): "Estimating Consumption Economies of Scale, Adult Equivalence Scales and Household Bargaining Power", Mimeo, Chesnut Hill, Boston College.

[33] Lundberg S.J. and R.A. Pollak (1993): "Separate Spheres Bargaining and the Marriage Market", Journal of Political Economy, 101, 988-1010.

[34] Lundberg S.J. and R.A. Pollak (1996): " Bargaining and Distribution in Marriage", Journal of Economic Perspectives, 10, 139-158.

[35] Lundberg S.J., R.A. Pollak and T.J. Wales (1996): " Do Husbands and Wives Pool Their Resources? Evidence from the U.K. Child Benefit", The Journal of Human Resources, 32, 3, 463-480.

[36] MaCurdy, T., D. Green et H. Paarsch (1990): "Assessing Empirical Approaches for Analysing Taxes and Labor Supply", Journal of Human Resources, 25, 415-490.

[37] Maitra, P. and R. Ray (2001): "Intra Household Resource Allocation And Their Impact On Expenditure Patterns: Comparative Evidence From South Africa And Pakistan", Australasian Econometric Society Meeting, Conference Proceedings, Peter C, B Phillips and B Hool (eds), University of Auckland.

[38] Manser, M. and M. Brown (1980): "Marriage and Household Decision Making: a Bargaining Analysis", International Economic Review, 21, 31-44.

[39] Mazzocco, M. (2002): "Household Intertemporal Behavior: Empirical Tests of the Collective Characterization", University of Chicago working paper.

[40] McElroy, M.B. and M.J. Horney (1981): "Nash-Bargained Household Decisions: Toward a Generalization of the Theory of Demand", International Economic Review, 22, 333-347.

[41] McElroy, M.B. (1990): "The Empirical Content of Nash-Bargained Household Behavior", Journal of Human Resources, 25, 559-583.

[42] McFadden, D. and K. Train (2000): "Mixed MNL Models for Discrete Response", Journal of Applied Econometrics, 15, 447-470.

[43] Small, K. A. and H. S. Rosen (1981): "Applied Welfare Economics with Discrete Models", Econometrica, 49, 105-130. 
[44] Van Soest, A. (1995): "Structural Models of Family Labor Supply: a Discrete Choice Approach", Journal of human Resources, 30, 63-88.

\section{Appendices}

\subsection{Data and sample selection}

The data used are from the second wave (1995) of the European Community Household Panel (ECHP). We select three samples (single men, single women, married couples) out of the dataset and restrict each of them according to the following criteria. First, adult members must be in the age bracket 25 55. Second, they must be engaged in salary jobs if they work (self-employed, farmers and students are excluded); ${ }^{32}$ they must be 'voluntarily' unemployed if they do not (registered unemployed are excluded). ${ }^{33}$ Third, extreme households are withdrawn, notably the ones receiving important level of non-labor income. Moreover, single individuals must not have children in the household; couples must have no more than 3 children and no other adults than the basic couple; households with working children are withdrawn. Wage rates are not provided directly and must be computed. ${ }^{34}$ At this stage of the selection process, Figure 5 presents the distribution of work hours for single men and women as well as husbands and wives.

The distribution of hours for single men and for husbands conveys to the exclusion of inactive men from our samples. Also, non-participation is excluded from the set of possible choices for single men and husbands in all the discrete models of labor supply at use in this study. After selection, all men participate, $24 \%$ of the wives do not and $16 \%$ of single women do not. Descriptive statistics for couples are provided in Table 18.

\subsection{Estimation of individual preferences on singles}

Parameters $\gamma^{c}$ and $\gamma^{l}$ are estimated separately and must verify the usual restrictions $1>\gamma^{c}>0$, $1>\gamma^{l}>0$ and $\gamma^{c}+\gamma^{l}=1$, which is done by imposing a posteriori normalization (the utility is rescaled by their sum).

Maximum likelihood estimations were computed on SAS (codes are available upon request). Results are reported in Table 19. All parameters are statistically different from zero at conventional levels except

\footnotetext{
${ }^{32}$ Self-employed and farmers are subject to income tax rules that may be very different (from the ones applied to earnings) and require information not available. Their labor supply behavior may also be rather different and would require a different modelling strategy altogether.

${ }^{33}$ One reason is the measurement difficulties connected with unemployment benefits. Another is that unemployment is considered as exogenous to the process at stake in the study.

${ }^{34}$ Individuals are asked to report the yearly wage income $Y W$, the number of months worked during the year $N M$ and the number of hours normally worked per week $H W$ so that hourly wage rate can be computed as $Y W /(N M \times H W \times 4.33)$.
} 

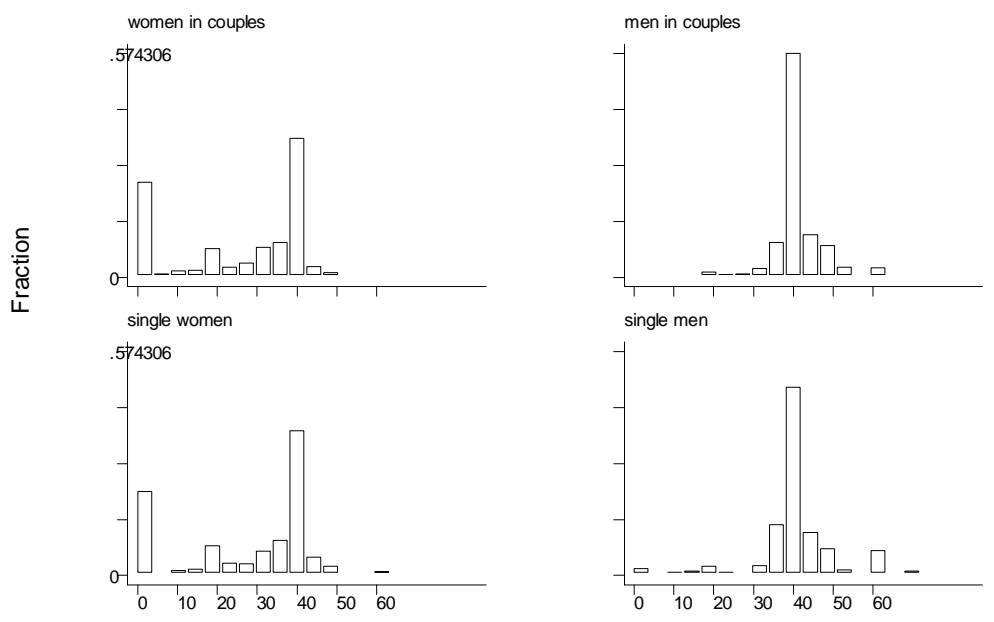

h

Figure 5: Actual labor supplies in the samples

Paris region (on the consumption term) for men. We assume that the regime chosen by each single is the one which gives the best hours prediction, once fulfilled the concavity restrictions. Looking at Table 20, it appears that regime 2 prevails. It seems to be chosen too often but many single men and single women actually do not exhibit regular preferences under regime 1.

On the whole, $64.2 \%$ of actual discretized labor supply is well predicted for single women. It amounts to $66.4 \%$ for single men. These figures hide important discrepancies. For single women, respectively $75 \%$ and $94 \%$ of non-working and full-time working situations are correctly predicted but only $11 \%$ of part-time jobs are. For single men, 90\% of them are predicted to work 40 hours a week, whereas $67 \%$ actually do so. Parameters $\gamma$ are presented in Table 21 once normalized. 
Table 1: preference parameters, power index and consumption share

\begin{tabular}{lccccccc}
\hline \hline Variable & Mean & Std. dev. & Min. & $10 \%$ & Median & $90 \%$ & Max. \\
\hline$\beta_{f}^{l}$ & .432 & .049 & .280 & .365 & .435 & .497 & .553 \\
$\beta_{f}^{c}$ & .554 & .060 & .319 & .480 & .552 & .635 & .706 \\
$\delta$ & .014 & .058 & -.137 & -.040 & .003 & .085 & .345 \\
$\beta_{m}^{l}$ & .601 & .043 & .378 & .537 & .615 & .638 & .705 \\
$\beta_{m}^{c}$ & .385 & .036 & .251 & .348 & .381 & .438 & .535 \\
\hline$\mu$ & .511 & .078 & .167 & .467 & .5 & .6 & .867 \\
\hline$p$ & .598 & .078 & .105 & .535 & .591 & .682 & .895 \\
\hline
\end{tabular}

Table 2: preference parameters in function of the family size

\begin{tabular}{lcccc}
\hline \hline Variable / nb of children & 0 & 1 & 2 & 3 \\
\hline$\beta_{f}^{l}$ & .433 & .429 & .431 & .439 \\
$\beta_{f}^{c}$ & .550 & .561 & .554 & .544 \\
$\delta$ & .016 & .010 & .015 & .017 \\
$\beta_{m}^{l}$ & .602 & .603 & .599 & .598 \\
$\beta_{m}^{c}$ & .382 & .386 & .385 & .384 \\
\hline
\end{tabular}


Table 3: statistics of the distribution factors, wages and non-labor income

\begin{tabular}{cccc}
\hline Variable & Mean. & Median. & Std. Dev. \\
\hline REP & .749 & 0.67 & .39 \\
$w_{f}$ & 7.56 & 6.53 & 4.05 \\
$w_{m}$ & 10.27 & 8.72 & 6.01 \\
$y_{0}$ & 873 & 277 & 1762 \\
dage & -1.90 & -2 & 3.68 \\
dedu & -.26 & 0 & 3.09 \\
durate & -4.31 & -4.8 & 4.44 \\
\hline
\end{tabular}

Notes: $R E P$ : her relative earning power as explained in the text; $w_{f}$ : her wage rate (euros); $w_{m}$ : his wage rate (euros); $y_{0}$ : level of yearly total capital income (euros); dage: hers minus his age; dedu: hers minus his education level; durate: relevant male minus female unemployment rates (depend on age and education level).

Table 4: estimation of the power index

\begin{tabular}{lccc}
\hline \hline Coef. name & Variable & coef. & robust s.e. \\
\hline$\eta_{0}$ & constant & -0.083 & $(.056)$ \\
\hline$\eta_{1}$ & $R E P$ & $.391^{* *}$ & $(.081)$ \\
$\eta_{2}$ & $(R E P)^{2}$ & $-0.091^{* *}$ & $(.018)$ \\
$\eta_{3}$ & $w_{f}$ & -.001 & $(.004)$ \\
$\eta_{4}$ & $w_{m}$ & $-.009^{* *}$ & $(.003)$ \\
$\eta_{5}$ & $y_{0} / 100$ & $.002^{* *}$ & $(.000)$ \\
$\eta_{6}$ & dage & -.003 & $(.002)$ \\
$\eta_{7}$ & dedu & $-.007^{*}$ & $(.003)$ \\
$\eta_{8}$ & durate & $.006^{* *}$ & $(.002)$ \\
\hline Adj. R-squared & & 0.11 & \\
\hline
\end{tabular}

Notes: significance levels of 5 and $1 \%$ are noted ${ }^{*}$ and ${ }^{* *}$ respectively. The covariance matrix is robust to heteroscedasticity of unknown form. 
Table 5: elasticity of the power index to the REP variable

\begin{tabular}{cccccccccc}
\hline \hline Percentile & 1 & 5 & 10 & 25 & 50 & 75 & 90 & 95 & 99 \\
\hline Elasticity & .033 & .051 & .059 & .075 & .089 & .098 & .096 & .084 & .024 \\
\hline
\end{tabular}

Note: The elasticity is evaluated at different percentiles of the $R E P$ variable, other covariates kept constant at the sample median.

Table 6: Sensitivity of the elasticity of the power index to the REP variable

\begin{tabular}{|c|c|c|c|c|c|c|c|c|c|}
\hline Percentile & 1 & 5 & 10 & 25 & 50 & 75 & 90 & 95 & 99 \\
\hline$\widehat{\gamma}_{f}^{c}+a, \widehat{\gamma}_{f}^{l}-a, \widehat{\gamma}_{m}^{c}+a, \widehat{\gamma}_{m}^{l}-a$ & 0.013 & 0.022 & 0.025 & 0.033 & 0.041 & 0.049 & 0.055 & 0.057 & 0.053 \\
\hline$\widehat{\gamma}_{f}^{c}+a, \widehat{\gamma}_{f}^{l}-a, \widehat{\gamma}_{m}^{c}-a, \widehat{\gamma}_{m}^{l}+a$ & 0.014 & 0.021 & 0.025 & 0.031 & 0.036 & 0.038 & 0.034 & 0.027 & -0.010 \\
\hline$\widehat{\gamma}_{f}^{c}-a, \widehat{\gamma}_{f}^{l}+a, \widehat{\gamma}_{m}^{c}+a, \widehat{\gamma}_{m}^{l}-a$ & 0.017 & 0.028 & 0.033 & 0.045 & 0.057 & 0.072 & 0.086 & 0.095 & 0.109 \\
\hline$\widehat{\gamma}_{f}^{c}-a, \widehat{\gamma}_{f}^{l}+a, \widehat{\gamma}_{m}^{c}-a, \widehat{\gamma}_{m}^{l}+a$ & 0.013 & 0.020 & 0.024 & 0.032 & 0.040 & 0.049 & 0.056 & 0.059 & 0.059 \\
\hline$\widehat{\gamma}_{f}^{c}+b, \widehat{\gamma}_{f}^{l}-b, \widehat{\gamma}_{m}^{c}+b, \widehat{\gamma}_{m}^{l}-b$ & 0.007 & 0.012 & 0.014 & 0.018 & 0.023 & 0.029 & 0.029 & 0.029 & 0.022 \\
\hline$\widehat{\gamma}_{f}^{c}+b, \widehat{\gamma}_{f}^{l}-b, \widehat{\gamma}_{m}^{c}-b, \widehat{\gamma}_{m}^{l}+b$ & 0.013 & 0.021 & 0.023 & 0.029 & 0.032 & 0.031 & 0.022 & 0.009 & -0.045 \\
\hline$\widehat{\gamma}_{f}^{c}-b, \widehat{\gamma}_{f}^{l}+b, \widehat{\gamma}_{m}^{c}+b, \widehat{\gamma}_{m}^{l}-b$ & 0.014 & 0.024 & 0.029 & 0.041 & 0.054 & 0.072 & 0.092 & 0.108 & 0.143 \\
\hline$\widehat{\gamma}_{f}^{c}-b, \widehat{\gamma}_{f}^{l}+b, \widehat{\gamma}_{m}^{c}-b, \widehat{\gamma}_{m}^{l}+b$ & 0.002 & 0.004 & 0.004 & 0.006 & 0.007 & 0.008 & 0.010 & 0.011 & 0.011 \\
\hline
\end{tabular}

Notes: Elasticities are evaluated at different percentiles of the $R E P$ variable, other covariates kept constant at the sample median. The parameters $\widehat{\gamma}_{i}^{j}$, for $i=f, m$ and $j=c, l$, are singles' estimates of preference parameters. The scalars $a$ and $b$ are respectively equal to 0.05 and 0.1 .

Table 7: variation in tax liability after the reform (no behavioral responses)

\begin{tabular}{lcccc}
\hline & no change & \multicolumn{3}{c}{ change in tax liability } \\
\hline \multicolumn{1}{l}{ tax } & pre-reform tax & post-reform tax & relative increase \\
\hline of households & 35.5 & 64.5 & 64.5 & $63.3^{*}$ \\
Mean & 2228 & 3322 & 4243 & $67 \%$ \\
Median & 1767 & 1849 & 2530 & $19 \%$ \\
Std. Dev. & 2346 & 4777 & 5512 & 1.02 \\
$10 \%$ & 0 & 397 & 932 & $2 \%$ \\
$90 \%$ & 4822 & 7269 & 8528 & $188 \%$ \\
\hline
\end{tabular}

* Around $1.2 \%$ of the couples did not pay tax before the reform and pay a yearly average of 641 euros after the reform. Annual tax liabilities are given in euro. 
Table 8: impact of the reform on distribution of wealth and welfare (no behavioral response)

\begin{tabular}{cccc}
\hline \hline & Pre-reform & Post-reform & variation \\
\hline$c$ & 636 & 624 & $-1.9 \%$ \\
$c_{f}$ & 360 & 353 & $-1.9 \%$ \\
$c_{m}$ & 276 & 271 & $-1.9 \%$ \\
$U_{f}$ & 100 & 99.73 & $-0.27 \%$ \\
$U_{m}$ & 100 & 99.77 & $-0.23 \%$ \\
$W$ & 100 & 99.74 & $-0.26 \%$ \\
\hline
\end{tabular}

Note: figures correspond to mean values over the sample of couples; consumptions are given in euros/week; post-reform utilities are expressed relatively to pre-reform utilities normalized to 100; the same for total welfare.

Table 9: labor supply response after the unitary effect: variation in hours/week

\begin{tabular}{lccccc}
\hline \hline wives $\backslash$ husbands & -10 & -5 & 0 & +5 & Total \\
\hline 0 & 0 & 1.67 & 75.9 & 0.63 & 78.19 \\
-10 & .28 & 1.46 & 5 & 0 & 6.74 \\
+20 & .35 & 3.75 & 10.83 & 0 & 14.93 \\
+30 & .14 & 0 & 0 & 0 & .14 \\
\hline Total & .76 & 6.88 & 91.73 & .63 & 1440 \\
\hline
\end{tabular}

Note: entries in the table give frequencies (in\%), except the last cell which gives the number of observations. 
Table 10: post-reform distribution of wealth and welfare (with and without unitary response)

\begin{tabular}{cccc}
\hline \hline & no response & unitary response & variation \\
\hline$c$ & 624 & 642 & $+2.9 \%$ \\
$c_{f}$ & 353 & 363 & $+2.9 \%$ \\
$c_{m}$ & 271 & 279 & $+2.9 \%$ \\
$U_{f}$ & 99.73 & 99.55 & $-0.2 \%$ \\
$U_{m}$ & 99.77 & 100.20 & $+0.4 \%$ \\
$W$ & 99.74 & 99.79 & $+0 . .05 \%$ \\
\hline
\end{tabular}

Note: figures correspond to mean values over the sample of couples; consumptions are given in euros/week; post-reform utilities (with or without unitary responses) are expressed relatively to pre-reform utilities normalized to 100; the same for total welfare.

Table 11: joint variation in REP and the power index

\begin{tabular}{lcccccc}
\hline & \multicolumn{3}{c}{$R E P$} & & & $\mu$ \\
& & & & & \\
& Pre-reform & Post-reform & variation & Pre-reform & Post-reform & variation \\
\hline Mean & .749 & .839 & $14.97 \%$ & .511 & .516 & $1.09 \%$ \\
Std. Dev. & .39 & .39 & .09 & .078 & .077 & .005 \\
Min. & .09 & .16 & $-2.3 \%$ & .167 & .169 & $-.30 \%$ \\
$10 \%$ & .35 & .43 & $6.4 \%$ & .467 & .471 & $.48 \%$ \\
Median & .67 & .76 & $12.8 \%$ & .5 & .505 & $1.02 \%$ \\
$90 \%$ & 1.20 & 1.30 & $26.2 \%$ & .6 & .605 & $1.75 \%$ \\
Max. & 4.58 & 4.59 & $84.5 \%$ & .867 & .870 & $3.10 \%$ \\
\hline
\end{tabular}

Table 12: average labor supply

\begin{tabular}{cccc}
\hline \hline & Pre-reform & Post- reform and unitary effect & Post-reform and collective effect \\
\hline$h_{f}(\mathrm{~h} /$ week $)$ & 26.2 & 29.9 & 29.8 \\
$h_{m}(\mathrm{~h} /$ week $)$ & 42.2 & 41.8 & 42.0 \\
\hline
\end{tabular}

Note: figures correspond to mean values over the sample of couples; consumptions are given in euro/week; post-reform utilities (with unitary or collective responses) are expressed relatively to pre-reform utilities normalized to 100; the same for total welfare. 
Table 13: post-reform distribution of wealth and welfare (with unitary vs collective responses)

\begin{tabular}{cccc}
\hline \hline & unitary response & collective response & variation \\
\hline$c$ & 642 & 643 & $+0.08 \%$ \\
$c_{f}$ & 363 & 367 & $+0.76 \%$ \\
$c_{m}$ & 279 & 276 & $-0.79 \%$ \\
$U_{f}$ & 99.55 & 99.68 & $+0.13 \%$ \\
$U_{m}$ & 100.20 & 100.03 & $-0.17 \%$ \\
$W$ & 99.79 & 99.89 & $+0.09 \%$ \\
\hline
\end{tabular}

Table 14: impact of the reform on individual and total welfare

\begin{tabular}{cccc}
\hline \hline welfare & no reponse & unitary response & collective response \\
\hline$U_{f}$ & 99.73 & 99.55 & 99.68 \\
$U_{m}$ & 99.77 & 100.20 & 100.03 \\
$W$ & 99.75 & 99.80 & 99.89 \\
\hline
\end{tabular}

Note: post-reform utilities (with unitary, collective or no responses) are expressed relatively to pre-reform utilities normalized to 100; the same for total welfare.

Table 15: distributional effect on average labor supplies

\begin{tabular}{ccccc}
\hline \hline$\mu$ & Post- unitary effect & \multicolumn{2}{c}{ Post- distributional effect } \\
& & $\mu+1 \%$ & $\mu+2.5 \%$ & $\mu+5 \%$ \\
\hline$h_{f}(\mathrm{~h} /$ week $)$ & 29.9 & 29.8 & 29.5 & 29.1 \\
$h_{m}$ (h/week) & 41.8 & 41.95 & 42.1 & 42.4 \\
\hline
\end{tabular}


Table 16: labor supply response of uniform rises of the power index

\begin{tabular}{lcccccccccccc}
\hline & \multicolumn{1}{c}{$\mu+1 \%$} & \multicolumn{1}{c}{$\mu+2.5 \%$} & \multicolumn{5}{c}{$\mu+5 \%$} \\
\hline wives $\backslash$ husbands & 0 & 5 & 10 & Total & 0 & 5 & 10 & Total & 0 & 5 & 10 & Total \\
\hline-20 & 0 & .1 & 0 & .1 & .2 & .3 & 0 & .5 & .6 & .5 & .1 & 1.1 \\
-10 & .3 & .1 & .2 & .6 & 2.1 & .7 & .3 & 3.1 & 3 & 2.4 & .6 & 6 \\
0 & 97.7 & 1.3 & .2 & 99.2 & 92.8 & 3.3 & .3 & 96.4 & 85.8 & 6.4 & .7 & 92.9 \\
\hline Total & 98 & 1.5 & .4 & 1440 & 95.1 & 4.3 & .6 & 1440 & 89.3 & 9.3 & 1.4 & 1440 \\
\hline
\end{tabular}

Note: entries in the table give frequencies (in\%), except the last cell (bottom right) of each column, which gives the number of observations.

Table 17: impact of uniform rises of the power index $\mu$

\begin{tabular}{ccccccccc}
\hline \hline$\mu$ & \multicolumn{3}{c}{$U_{f}$} & \multicolumn{5}{c}{$U_{m}$} \\
& Mean & $10 \%$ & Median & $90 \%$ & Mean & $10 \%$ & Median & $90 \%$ \\
\hline $1 \%$ & $+.12 \%$ & $+.06 \%$ & $+.08 \%$ & $+.09 \%$ & $-.17 \%$ & $-.16 \%$ & $-.09 \%$ & $-.07 \%$ \\
$2.5 \%$ & $+.30 \%$ & $+.16 \%$ & $+.20 \%$ & $+.23 \%$ & $-.41 \%$ & $-.60 \%$ & $-.23 \%$ & $-.17 \%$ \\
$5 \%$ & $+.60 \%$ & $+.32 \%$ & $+.39 \%$ & $+1.37 \%$ & $-.84 \%$ & $-1.85 \%$ & $-.47 \%$ & $-.35 \%$ \\
\hline
\end{tabular}


Table 18: descriptive statistics for selected couples

\begin{tabular}{cccccc}
\hline \hline & obs. ${ }^{*}$ & Mean & Std. dev. & Min. & Max. \\
\hline Weekly work hours husband $\#$ & 1,440 & 41.2 & 7.9 & 8 & 84 \\
Weekly work hours wife\# & 1,096 & 33.8 & 9.7 & 2 & 70 \\
Hourly gross wage rate husband (in euro) & 1,440 & 10.3 & 6 & 3.1 & 91.4 \\
Hourly gross wage rate wife (in euro) & 1,096 & 8.4 & 4.3 & 3.1 & 37 \\
Age husband & 1,440 & 40.3 & 7.6 & 25 & 54 \\
Age wife & 1,440 & 38.4 & 7.6 & 25 & 55 \\
Dummy for Paris region & 1,440 & .17 & .38 & 0 & 1 \\
Dummy for children & 1,440 & .84 & .37 & 0 & 1 \\
Number of children & 1,440 & 1.53 & 0.94 & 0 & 3 \\
Dummy for education husband & 1,440 & .36 & .48 & 0 & 1 \\
Dummy for education wife & 1,440 & .36 & .48 & 0 & 1 \\
\hline
\end{tabular}

Note: dummy for Paris region: 1=Paris region; dummy for education: 1=high school or university degree.

*: number of observations; for hours worked and wages, this is the number of participating individuals, followed by the corresponding statistics.

\#: with the discretization used in the study, we have for the husbands: mean=42.6, $\min =40$, max $=60$, and for the wives: mean $=34.3$, in $=0$, $\max =50$. 


\section{Table 19: Mixed logit estimates for single individuals (two mass points)}

\begin{tabular}{|c|c|c|}
\hline variable & coef. single men & coef. single women \\
\hline \multicolumn{3}{|c|}{ Marginal propensity for leisure $\gamma^{l}$ : } \\
\hline Age & $-8.81(2.03)$ & $5.05(1.20)$ \\
\hline Education & $-40.89(7.51)$ & $-2.27(.59)$ \\
\hline Paris region & $-3.03(1.04)$ & $-3.27(.77)$ \\
\hline \multicolumn{3}{|c|}{ Marginal propensity for consumption $\gamma^{c}$ : } \\
\hline Age & $-2.75(1.09)$ & $9.03(3.16)$ \\
\hline Education & $-27.27(5.53)$ & $-0.56(.29)$ \\
\hline Paris region & $0.37(.71)$ & $-1.19(.39)$ \\
\hline Age $\times$ age & / & $-4.17(1.58)$ \\
\hline \multicolumn{3}{|c|}{ Heterogeneity on leisure: } \\
\hline$\theta_{l 1}$ & $8.72(2.16)$ & $-3.23(1.33)$ \\
\hline$\theta_{l 2}$ & $58.99(7.61)$ & $46.87(10.98)$ \\
\hline \multicolumn{3}{|c|}{ Heterogeneity on consumption: } \\
\hline$\theta_{c 1}$ & $2.55(1.13)$ & $-4.05(1.48)$ \\
\hline$\theta_{c 2}$ & $37.23(5.67)$ & $53.88(12.84)$ \\
\hline \multicolumn{3}{|c|}{ Heterogeneity probablility: } \\
\hline$\pi_{1}$ & $0.18(.06)$ & $0.57(.03)$ \\
\hline Log-likelihood & -256.54 & -397.86 \\
\hline
\end{tabular}

Note : Education is an indicator for high school or university degree. Age is actual age divided by 40 . Paris region equals 1 if the couple lives in Paris region, 0 otherwise. Standard errors are given in brackets. The asymptotic standard error for the heterogeneity parameter was computed with the Delta method. 
Table 20: estimated probabilities and frequencies of the regimes

\begin{tabular}{lcccc}
\hline \hline & \multicolumn{2}{c}{ Single men } & \multicolumn{2}{c}{ Single women } \\
Regime $r$ & est. prob. $\pi_{r}$ & frequency & est. prob. $\pi_{r}$ & frequency \\
\hline 1 & .18 & .06 & 0.57 & 0.25 \\
2 & .82 & .94 & 0.43 & 0.75 \\
\hline
\end{tabular}

Table 21: normalized marginal propensities of singles

\begin{tabular}{lccccccc}
\hline \hline Variable & Coefficient & Std. dev. & Min. & $10 \%$ & Median & $90 \%$ & Max. \\
\hline$\gamma_{f}^{l}$ & .52 & .15 & .35 & .37 & .47 & .80 & .92 \\
$\gamma_{f}^{c}$ & .48 & .15 & .08 & .20 & .53 & .62 & .65 \\
\hline$\gamma_{m}^{l}$ & .61 & .03 & .52 & .57 & .62 & .63 & .87 \\
$\gamma_{m}^{c}$ & .39 & .03 & .13 & .37 & .38 & .43 & .48 \\
\hline
\end{tabular}

